\title{
Advances in targeting the transforming growth factor $\beta 1$ signaling pathway in lung cancer radiotherapy (Review)
}

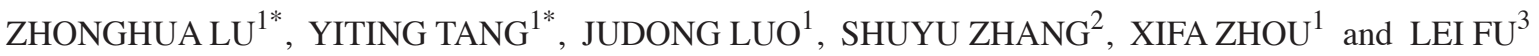 \\ ${ }^{1}$ Department of Radiation Oncology, Changzhou Cancer Hospital, Soochow University, Changzhou, Jiangsu 213001; \\ ${ }^{2}$ Department of Radiation Biology, School of Radiation Medicine and Protection and Jiangsu Provincial Key \\ Laboratory of Radiation Medicine and Protection, Medical College of Soochow University, Suzhou, Jiangsu 215123; \\ ${ }^{3}$ Department of Radiation Oncology, Shandong Cancer Hospital and Institute, Shandong Cancer Hospital Affiliated \\ to Shandong University, Shandong Academy of Medical Sciences, Jinan, Shandong 250117, P.R. China
}

Received January 17, 2016; Accepted July 21, 2017

DOI: $10.3892 / 01.2017 .6991$

\begin{abstract}
Lung cancer was demonstrated to be the most lethal type of malignant tumor amongst humans in the global cancer statistics of 2012. As one of the primary treatments, radiotherapy has been reported to induce remission in, and even cure, patients with lung cancer. However, the side effects of radiotherapy may prove lethal in certain patients. In past decades, the transforming growth factor $\beta 1$ (TGFB1) signaling pathway has been revealed to serve multiple functions in the control of lung cancer progression and the radiotherapy response. In mammals, this signaling pathway is initiated through activation of the TGFB1 receptor complex, which signals via cytoplasmic SMAD proteins or other downstream signaling pathways. Multiple studies have demonstrated that TGFB1 serves important functions in lung cancer radiotherapy. The present study summarized and reviewed recent progress in elucidating the function of the TGFB1 signaling pathway in predicting radiation pneumonitis, as well as current strategies for targeting the TGFB1 signaling pathway in lung cancer radiotherapy, which may provide potential targets for lung cancer therapy.
\end{abstract}

Correspondence to: Dr Xifa Zhou, Department of Radiation Oncology, Changzhou Cancer Hospital, Soochow University, 1 North Huaide Road, Changzhou, Jiangsu 213001, P.R. China

E-mail: zhouxifacz@sina.com

Dr Lei Fu, Department of Radiation Oncology, Shandong Cancer Hospital and Institute, Shandong Cancer Hospital Affiliated to Shandong University, Shandong Academy of Medical Sciences, Jinan, Shandong 250117, P.R. China

E-mail: fuiray@126.com

*Contributed equally

Key words: lung cancer, transforming growth factor $\beta 1$, radiotherapy

\section{Contents}

1. Introduction

2. TGFB1 signaling pathway

3. TGFB1 serves as a predictor of radiation pneumonitis (RP) in lung cancer radiotherapy

4. Predictive function of TGFB1 in lung cancer radiotherapy

5. Preclinical and clinical strategies for targeting the TGFB1 signaling pathway in lung cancer radiotherapy

6. Conclusions

\section{Introduction}

Lung cancer was the most lethal type of malignant tumor amongst humans in the global cancer statistics of 2012 (1). By morphological type, lung cancer is primarily divided into small cell lung cancer (SCLC) and non-SCLC (NSCLC) (2). Lung cancer cells are sensitive to radiotherapy, and thoracic radiotherapy can eradicate chemotherapy-resistant tumor cells $(3,4)$. A retrospective study demonstrated that clinical outcomes following stereotactic body radiotherapy are equal or superior to surgery alone for overall survival in patients with stage I-II NSCLC (3). Two meta-analyses have indicated a statistically significant advantage with respect to overall survival associated with limited-disease SCLC following radiotherapy $(5,6)$. However, radiation-induced pulmonary injury, local recurrence and distant metastasis have become substantial challenges to the successful management of lung cancer (7).

Due to its non-specificity, radiation kills rapidly mitosing cells, irrespective of whether they are cancerous or normal, resulting in damage to tissues that have an increased turnover rate, including skin, lung, bone marrow and gut epithelium (8). At present, the prognostic factors of lung cancer therapy are widely studied (9-12). A prior study revealed that the $\mathrm{DiAcSpm} /$ cutoff ratio (DASr) is significantly increased in NSCLC, and the DASr was revealed to be an independent negative prognostic indicator in patients with NSCLC who underwent complete resection (13). The overexpression of SRY-box 2 may serve as a positive prognostic factor in patients with stage III squamous cell lung cancer receiving adjuvant radiotherapy (14). Although understanding of the 
molecular mechanisms underlying the development of normal lung tissue injury and tumor tissue response in radiotherapy has improved, transforming growth factor $\beta 1$ (TGFB1) is the most important factor among the numerous cytokines and growth factors that contribute to the radiation-induced injury process (15). The present study reviewed the function of TGFB1 in radiation-induced pulmonary injury and lung cancer response to radiotherapy, aiming to discuss the clinical use of this cytokine in lung cancer radiotherapy.

\section{TGFB1 signaling pathway}

The TGFB family is a group of pleiotropic growth factors that activate signal transduction cascades that serve important functions in carcinogenesis and tumor progression (16). TGFB1, a ligand of the TGFB signaling pathway, is present in numerous cell types. TGFB1 is most highly concentrated in healing wounds, where it is released in large quantities from platelets (17). TGFB1 then recruits monocytes and macrophages to the injury site (18), inhibits epithelial cell proliferation and enhances fibroblast maturation into post-mitotic fibrocytes that increase fibrous tissue production $(19,20)$, thereby accelerating angiogenesis and extracellular matrix formation (21-23). In cancer cells, TGFB1 serves a dual role. Initially, it functions as a tumor suppressor by inhibiting cell growth and inducing apoptosis (24). However, during the later stages of tumor development, TGFB1 functions as a tumor promoter by inducing the epithelial-mesenchymal transition (EMT) in cancer cells, resulting in increased invasion and metastasis $(24,25)$.

The signal transduction initiates with the TGFB1 ligand binding to and activating TGFB receptor II (TGFBRII), which then phosphorylates TGFBRI through activating its kinase. Phosphorylated TGFBRI phosphorylates the downstream elements of the signaling pathway via the regulatory SMADs (R-SMADs) SMAD2 and SMAD3, in the C-terminus of these R-SMADs. Phosphorylated SMAD2 may form a stable complex with SMAD3 and the co-SMAD SMAD4 and the resulting SMAD complex is then translocated into the nucleus (Fig. 1). This SMAD complex interacts with multiple transcription factors, which further increases their binding affinity and specificity for the target gene promoters, resulting in gene transcription alterations $(24,25)$. Inhibitory SMAD may bind TGFBRI and attenuate signaling pathway activation (26). TGFB1 may also signal via multiple alternative cascades, including the mitogen-activated protein kinase and protein kinase B signaling pathways $(27,28)$, which may further mediate growth by inhibiting cell cycle progression and inducing apoptosis (27).

\section{TGFB1 serves as a predictor of radiation pneumonitis (RP) in lung cancer radiotherapy}

Radiotherapy is the primary treatment for patients with inoperable, locally advanced lung cancer. This conventional treatment has been reported to induce remission in and cure patients with the disease (29). However, with conformal treatment planning, the side effects can prove lethal and radiotherapy may be ineffective due to the limitations imposed by normal tissue. This is particularly true in tumors that require increased doses of radiation or are located within or adjacent

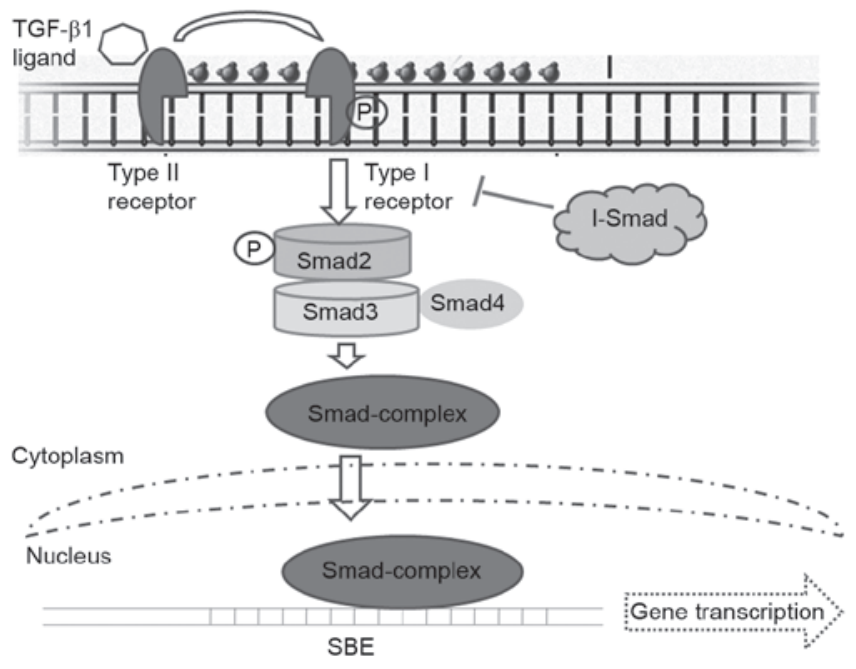

Figure 1. TGF- $\beta 1$ signaling pathway. TGF- $\beta$ receptors phosphorylate intracellular SMAD proteins following ligand-binding. SMAD2 is phosphorylated by TGF- $\beta$ receptor I and subsequently forms a complex with SMAD3 and the co-SMAD SMAD4. This complex is then transported into the nucleus where it binds an SBE and induces the transcription of TGF- $\beta$-dependent genes. I-SMAD may bind TGF- $\beta$ receptor I and attenuate pathway activation. TGF- $\beta$, transforming growth factor $\beta$; I-SMAD, inhibitory SMAD; SBE, SMAD binding element; $P$, phosphorylated.

to sensitive organs (30). RP is considered the most serious, dose-limiting complication of radiotherapy (30). Growth factors are synthesized and secreted between a few $\mathrm{h}$ and days following irradiation, and may then continue for months. Cytokine plasma levels, including those of tumor necrosis factor, interleukin (IL)-1 $\beta$, IL-6, and TGFB1 serve a predictive function for RP; the influence of tumor-derived cytokine production on circulating plasma levels in irradiated patients with NSCLC was evaluated in a previous study (30). The expression of TGFB1 increased in a dose-dependent manner following exposure to ionizing radiation (31). TGFB1 was reported as one of the most important growth factors among the molecules expressed in tissues following radiation exposure, and is associated with the incidence of RP (32). Multiple studies have established the positive association between the severity of radiation-induced lung injury and TGFB1 signaling activation $(33,34)$. In a rat model of radiation-induced lung injury, fibrosis developed and was accompanied by increased expression of TGFB1 and activation of the TGFB1 signaling pathway (35). Furthermore, TGFB1 activation by radiation has been demonstrated to occur at decreased doses and in an approximately dose-dependent manner between $10 \mathrm{cGy}$ and 5 Gy (36). Serially measuring plasma TGFB1 levels has been proposed to estimate the risk of RP and to assist in determining whether additional dose escalation may be safely applied in chemotherapy $(37,38)$. Anscher et al (38) assessed whether TGFB1 may also be used to predict the risk of developing pulmonary injury following radiotherapy. Anscher et al (39) performed a small clinical trial and determined that it was feasible to use TGFB1 to guide radiation dose selection for patients with lung cancer. Furthermore, the expression of TGFB1 in the sputum was reported to be a factor for predicting RP (40). TGFB1 may be expressed in the sputum of patients with lung cancer, in whom macrophages are the main sources 


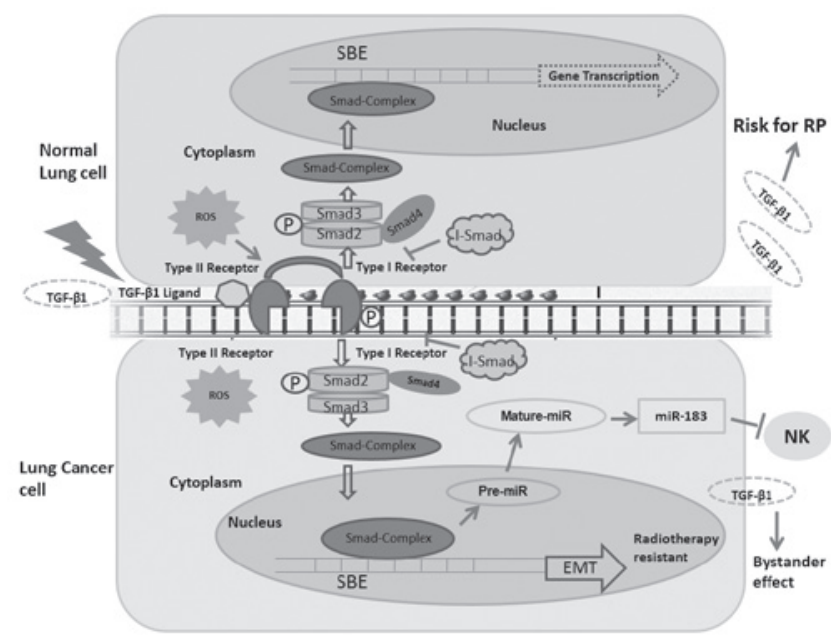

Figure 2. Function of TGF- $\beta 1$ in normal lung and lung cancer cell responses to radiotherapy. In normal lung cells: ROS are produced following exposure to radiation; ROS subsequently activate the TGF- $\beta 1$ signaling pathway and stimulate TGF- $\beta 1$ secretion into the plasma, a potential risk factor for radiation-induced lung injury (47). In lung cancer cells: Regulation of the expression of certain miRs follows TGF- $\beta 1$ signaling pathway activation the TGF- $\beta 1$ signaling molecules diffuse to and activate bystander cells (61) miR-183 may transcriptionally be regulated by the TGF- $\beta 1$ signaling pathway to silence NK cells by repressing DAP12 transcription, which is critical for surface NK receptor stabilization and downstream signal transduction (62); TGF- $\beta 1$ exposure induces EMT and radiotherapy resistance (67). TGF- $\beta$, transforming growth factor $\beta$; EMT, epithelial-mesenchymal transition; NK, natural killer; ROS, reactive oxygen species; RP, radiation pneumonitis I-SMAD, inhibitory SMAD; SBE, SMAD binding element; P, phosphorylated; miR, microRNA.

of TGFB1 expression (40). Patients with increased TGFB1 expression in the sputum following radiotherapy were associated with an increased incidence of RP compared with those with decreased TGFB1 expression (40). All the aforementioned approaches resulted in decreased expression and activation of TGFB1 and decreased activation of the SMAD-dependent TGFB1 signaling pathway (37-40). The observations of Anscher et al $(38,39)$ suggests that plasma TGFB1 measurements may assist in identifying whether patients with lung cancer are candidates for radiation dose escalation or decrease. A previous study also revealed that the serum expression of TGFB1 increased significantly four weeks, and reached the highest recorded level eight weeks, following irradiation in a rat model (41). Furthermore, downregulating TGFB1 protected against radiation-induced lung injury in the rat model (41).

Meanwhile, circulating TGFB1 levels in lung cancer patients are elevated compared with people without cancer (42). The reason for the higher levels of TGFB1 appears to be associated with greater production and altered bioavailability of this cytokine (43). The mannose-6-phosphate/insulin-like growth factor receptor type II (M6P/IGF2R) was reported to serve a crucial function in these feedback process (44). Kong et al (45) demonstrated that if patients with lung cancer exhibited a loss of heterozygosity in M6P/IGF2R, they were significantly more likely to exhibit increased plasma TGFB1 levels and to develop radiation-induced lung injury compared with those with heterozygosity in M6P/IGF2R. Reactive oxygen species (ROS) are produced following radiation exposure (46), and have been revealed to activate latent TGFB1 expression (Fig. 2) (47). Mice genetically engineered to overexpress one of the isoforms of superoxide dismutase have been demonstrated to resist radiation-induced lung injury (48). Similarly, the administration of superoxide dismutase mimetic has been revealed to decrease the severity of lung injury in rats, in vivo (49).

However, the results of using TGFB1 levels to predict the risk of lung injury have been inconsistent among studies (50). A previous study reported that the return of plasma TGFB1 levels to the normal range following radiotherapy accurately predicted that patients would not develop RP (38). Another study failed to confirm that TGFB1 serves as a predictor of RP in lung cancer radiotherapy (51). Jaeger et al (37) did not confirm that increased levels of TGFB1 following the end of radiotherapy represented an independent additional risk factor for developing symptomatic RP. Further study revealed that CT/CC genotypes of the TGFB1 rs1982073:T869C gene were associated with a decreased risk of RP in patients with lung cancer treated with definitive radiotherapy compared with the other genotypes, and therefore may serve as reliable predictors of RP (52).

\section{Predictive function of TGFB1 in lung cancer radiotherapy}

Multiple studies have demonstrated that increased serum levels of TGFB1 following the initiation of radiation therapy were associated with radiation-induced lung injury, as aforementioned (32-34). Changes in circulating TGFB1 levels during radiation therapy may also be associated with the prognosis of patients with locally advanced NSCLC (53). In locally advanced NSCLC, decreased expression of TGFB1 during radiotherapy is associated with a more favorable prognosis (54).

Radiation may trigger the synthesis and secretion of TGFB1, and the activation of the intracellular TGFB signaling pathway, as evidenced by the phosphorylation of SMAD and transcriptional activation of a TGFB-responsive reporter gene in lung cancer cells (54). Radiation induced cells to increase their migration in response to recombinant TGFB1, and this was accompanied by the upregulation of TGFBR expression (54). An increasing slope of the dose-response curve was associated with the C-509T single nucleotide polymorphism, suggesting that a polymorphism within the promoter region of the TGFB1 gene is associated with radiation sensitivity (55). Breast cancer cells pre-treated with the TGFB1 small molecule inhibitor LY364947 were radiosensitized, irrespective of sensitivity to TGFB1-induced growth inhibition (56). Consistent with increased clonogenic cell death, DNA damage was significantly decreased in breast cancer cells pretreated in vitro or in vivo with a TGFBRI kinase inhibitor (56). Furthermore, TGFB1-neutralizing antibodies increased radiation sensitivity and significantly delayed tumor growth in response to single and fractionated radiation exposure (56). These results suggest that inhibiting TGFB1 activity prior to radiation attenuates the DNA damage response and increases the radiosensitivity of breast cancer cells (56). However, whether TGFB1 may serve as an effective sensitizer in lung cancer radiotherapy has not yet been reported.

The signaling pathway induced by TGFB1 serves an important function in lung cancer cell growth and differentiation, and this pathway is associated with a significant predictive value in lung cancer radiotherapy. The present study further reviewed 
reports on TGFB1-associated microRNAs (miRNA/miR) and the mechanisms underlying EMT in lung cancer radiotherapy.

TGFB1 signaling pathway-associated miRNAs may influence lung cancer development and anti-metastatic treatment. Multiple studies have demonstrated that miRNAs are associated with cancer development, invasion and metastasis $(57,58)$, suggesting they may serve a function in lung cancer treatment. Previously, SMAD proteins of the TGFB1 signaling pathway were revealed to regulate miRNA expression through transcriptional and post-transcriptional mechanisms (25). Animal studies with transgenic mouse models supported the conclusion that activating TGFB1 increased the incidence of lung metastases from breast cancer (59), whereas blocking TGFB1 activity decreased metastatic potential (60). An in vitro study demonstrated that the TGFB1-miR-21-ROS signaling pathway in bystander cells was critical for bystander responses to manifest in NSCLC (Fig. 2) (61). Jiang et al (61) demonstrated that when NSCLC cells were irradiated with 5 Gy X-rays, the TGFB1 signaling pathway was activated and the cells released certain signaling molecules, including TGFB1, into the surrounding medium. These signaling molecules diffused to bystander cells and activated the TGFB1-miR-21-ROS signaling pathway in these bystander cells (61). A prior study also revealed that TGFB-induced miR-183 silenced tumor-associated natural killer (NK) cells (Fig. 2) (62). However, the tumor cells evaded NK cell surveillance by generating an immunosuppressive environment through multiple factors, including TGFB1 (63). NK cells and cytotoxic T lymphocytes exposed to TGFB1 did not kill tumor cells in humans or mice, indicating that TGFB1 exhibited an immunosuppressive function (64). Consequently, elevated serum TGFB1 levels were associated with poorer prognosis, and observed in the metastatic stage of numerous types of cancer (65). In vivo depletion of TGFB1 or blockade of the TGFB1 signaling pathway may restore the NK cell-mediated anti-tumor response.

TGFB1 exposure results in EMT and the inhibition of growth arrest and apoptosis. To improve understanding of the dual tumor-suppressive and tumor-promoting function of TGFB1 in cancer cells, Gal et al (66) assessed the response of mammary epithelial cancer cells to short and long-term TGFB1 exposure. Cell proliferation was arrested and apoptosis was induced following exposure to TGFB1 for 2-5 days, whereas the surviving cells underwent EMT and became resistant to proliferation arrest and apoptosis (66). EMT was reversed using a pharmacological TGFBRI kinase inhibitor or by ceasing TGFB1 exposure. In addition, the downregulation of TGFB-dependent signaling pathways in the transdifferentiated (TD) cells was reversed, and proliferation arrest and apoptosis induced, upon ceasing TGFB1 exposure (66). This previous study concluded that suppressing the anti-proliferative TGFB1 signaling pathway in TD cells may permit TGFB-dependent survival and EMT-enhancing signaling pathways to function to stimulate proliferation, survival and EMT at low, but sufficient, levels (66). Therefore, the TGFB1 signaling pathway may be modulated to facilitate switching from tumor suppression to progression (66).

EMT is a determinant of radiotherapy sensitivity in NSCLC (Fig. 2) (67). Yasushi et al (67) evaluated the association between EMT and radiotherapy sensitivity using NSCLC cells induced to undergo EMT with TGFB1. The expression of EMT markers in tumor specimens obtained from patients with lung cancer were immunohistochemically analyzed. EMT resulted in increased malignant potential and reduced sensitivity to radiation, and further altered certain cells into therapy-resistant sub-lines with TGFB1 (67). In addition, increased evidence of EMT was detected in surgically resected specimens following radiotherapy compared with biopsy specimens prior to radiation treatment (66). The patients with EMT marker-positive tumors were associated with a decreased disease-free survival rate compared with those with EMT marker-negative tumors (67). It was concluded that the TGFB1 signaling pathway was associated with insensitivity to radiotherapy due to EMT induction (67). Novel therapeutic combinations using TGFB1 inhibitors or EMT-signaling inhibitors may be required to circumvent the resistance of lung cancer to radiotherapy. Furthermore, another study suggested that radiation induced a migratory or invasive phenotype in carcinoma, including lung cancer cells in vitro, through hyper-activation of the TGFB1 signaling pathway (54).

However, a major challenge in developing accurate models of radiation-induced lung toxicity is inter-patient variation in inherent radiation sensitivity. The predictive value of TGFB1 in lung cancer radiotherapy and the mechanism underlying how the activation of the TGFB1 signaling pathway during radiotherapy contributes to metastasis, cancer stem cell formation and resistance to therapy via EMT induction, require further study.

\section{Preclinical and clinical strategies for targeting the TGFB1 signaling pathway in lung cancer radiotherapy}

Radiation oncologists have focused on tolerating tissue injury by limiting the dose or volume of the normal tissue receiving radiation $(68,69)$. Although these dose-volume associations have received attention to more precisely correlate dose, volume and the risk for normal tissue injury, certain disadvantages that may influence the risk of treatment-associated complications remain (70). TGFB1 represents a target for molecular therapies designed to prevent or inhibit normal tissue injury following cancer radiotherapy (71). The evidence supporting the critical function of TGFB1 in the development of normal tissue injury following cancer therapy was aforementioned. The present study further reviewed the strategies aimed at preventing normal tissue injury and sensitizing tumor cells by targeting the TGFB1 signaling pathway.

Due to the vast number of potential targets in the TGFB1 signaling pathway, multiple approaches have been adopted in vitro to prevent the binding of TGFB1 to its receptor, including specific antibody-mediated neutralization of soluble TGFB, or dominant-negative inhibition of TGFBRI and TGFBRII $(71,72)$. The TGFB-specific approaches inhibited radiation-dependent TGFB1 secretion, the phosphorylation of SMAD and reporter gene activity, indicating that autocrine production of TGFB and the subsequent activation of TGFB1 induced these changes (54). After administering a single dose of $1.0 \mathrm{mg} / \mathrm{kg}$ anti-TGFB1 antibody, delivered with the final fraction of the right hemithorax irradiation, to Fischer rats, Anscher et al (72) demonstrated that, compared with in the rats receiving radiation alone, inhibited fibrosis, TGFB1 expression 
and TGFB1-induced signaling were observed in the rats treated with a combination of radiation and an anti-TGFB1 antibody. A TGFBRI inhibitor was also administered daily to a group of Sprague-Dawley rats with irradiated right lungs (72). The drug was administered from 7 days prior to irradiation until sacrifice, or for 3 weeks. There was significantly decreased fibrosis, TGFB1 expression and chronic oxidative stress in the treated irradiated group as compared with in the untreated irradiated group (72).

A prior study indicated that the TGFB1 signaling pathway may induce the overproduction of fibrous tissue in response to radiation through SMAD-independent signaling pathways, including the ABL proto-oncogene (ABL)1 signaling pathway (71). The drug imatinib, which inhibits the ABL1 signaling pathway, was reported to inhibit the development of pulmonary fibrosis in NIH-3T3 and AKR-2B MEFs and in mice models (73). TGFB1 was also revealed to signal via the Ras homolog family member D (RHOD)/Rho associated coiled-coil containing protein kinase (ROCK) signaling pathway, independent of the SMAD signal transduction cascade $(74,75)$. Targeting of the RHOD/ROCK signaling pathway has been revealed to protect against radiation enteritis. In addition, administering superoxide dismutase mimics has been revealed to decrease the severity of lung injury in a Fisher-344 rat model (49). Radiation sensitized cells and further upregulated the expression of TGFBRI and TGFBRII, resulting in an increase in lung and pancreatic carcinoma cell migration via EMT (54). Strategies for inhibiting EMT and inhibitors of TGFBRI and TGFBRII should be taken into consideration for minimizing radiotherapy side-effects in clinical practice. Otherwise, deregulation of the TGFB1 signaling pathway may be induced by oscillating miRNA levels, such as miR-183. Therefore, the use of therapeutic agents that facilitate the TGFB1 signaling pathway and silence the expression of miR-183 may represent a promising strategy for activating the immune system in lung therapy (62). These types of approach result in decreased activation of TGFB1 and the SMAD-dependent TGFB1 signaling pathway, and inhibit ROS production.

\section{Conclusions}

To conclude, information regarding multiple aspects of the TGFB1 signaling pathway in carcinogenesis has increased over the past years. TGFB1 is considered a critical cytokine in the development of late normal tissue injury following lung cancer radiotherapy (37-39). Monitoring TGFB1 in the plasma and screening for TGFB1 polymorphisms may assist in identifying normal tissue injury risk in patients with lung cancer $(38,52,55)$. Although the molecular mechanisms underlying the TGFB1 signaling pathway and the SMAD effector complex have been previously established $(24,25)$, upstream regulators of the TGFB1 signaling pathway and the mechanisms by which they regulate the components of the pathway as the tumor develops require further study. Strategies targeting TGFB1 have been demonstrated to decrease the severity of normal tissue injury in animal models $(41,76)$. However, determining how such strategies may be effectively and safely applied in humans requires further clinical assessment.

\section{Acknowledgements}

The present study was supported by Scientific Program of Jiangsu Province (grant nos. BE2015631 and BK20151174), Changzhou Scientific Program (grant nos. CJ20160015 and QN201503); Changzhou Municipal Commission of Health and Family Planning (grant nos. QN201604 and ZD201602) and Changzhou High Level Medical Talents Training Project (2016CZLJ026).

\section{References}

1. Torre LA, Bray F, Siegel RL, Ferlay J, Lortet-Tieulent J and Jemal A: Global cancer statistics, 2012. CA Cancer J Clin 65: 87-108, 2015.

2. Siegel RL, Miller KD and Jemal A: Cancer statistics, 2015. CA Cancer J Clin 65: 5-29, 2015.

3. Chang JY, Senan S, Paul MA, Mehran RJ, Louie AV, Balter P, Groen HJ, McRae SE, Widder J, Feng L, et al: Stereotactic ablative radiotherapy versus lobectomy for operable stage I non-small-cell lung cancer: A pooled analysis of two randomised trials. Lancet Oncol 16: 630-637, 2015.

4. Adamowicz K and Goszczynska-Matysiak E: Combining systemic therapies with radiation in non small cell lung cancer. Klin Onkol 28: 321-331, 2015.

5. Pignon JP, Arriagada R, Ihde DC, Johnson DH, Perry MC, Souhami RL, Brodin O, Joss RA, Kies MS, Lebeau B, et al: A meta-analysis of thoracic radiotherapy for small-cell lung cancer. N Engl J Med 327: 1618-1624, 1992.

6. Warde P and Payne D: Does thoracic irradiation improve survival and local control in limited-stage small-cell carcinoma of the lung? A meta-analysis. J Clin Oncol 10: 890-895, 1992.

7. Wan L, Pantel K and Kang Y: Tumor metastasis: Moving new biological insights into the clinic. Nat Med 19: 1450-1464, 2013.

8. Ma Y, Yang Y, Wang F, Wei Q and Qin H: Hippo-YAP signaling pathway: A new paradigm for cancer therapy. Int J Cancer 137: 2275-2286, 2015

9. Gazdar AF: Epidermal growth factor receptor inhibition in lung cancer: The evolving role of individualized therapy. Cancer Metastasis Rev 29: 37-48, 2010.

10. Tang Y, Geng Y, Luo J, Shen W, Zhu W, Meng C, Li M, Zhou X, Zhang $S$ and Cao J: Downregulation of ubiquitin inhibits the proliferation and radioresistance of non-small cell lung cancer cells in vitro and in vivo. Sci Rep 5: 9476, 2015.

11. Sridhar SS, Seymour L and Shepherd FA: Inhibitors of epidermal-growth-factor receptors: A review of clinical research with a focus on non-small-cell lung cancer. Lancet Oncol 4: 397-406, 2003.

12. Hirsch FR, Varella-Garcia M, Cappuzzo F, McCoy J, Bemis L, Xavier AC, Dziadziuszko R, Gumerlock P, Chansky K, West $\mathrm{H}$, et al: Combination of EGFR gene copy number and protein expression predicts outcome for advanced non-small-cell lung cancer patients treated with gefitinib. Ann Oncol 18: 752-760, 2007.

13. Takahashi Y, Sakaguchi K, Horio H, Hiramatsu K, Moriya S, Takahashi K and Kawakita M: Urinary N1, N12-diacetylspermine is a non-invasive marker for the diagnosis and prognosis of non-small-cell lung cancer. Br J Cancer 113: 1493-1501, 2015.

14. Yoon HI, Park KH, Lee EJ, Keum KC, Lee CG, Kim CH and Kim YB: Overexpression of SOX-2 is associated with better overall survival in squamous cell lung cancer patients treated with adjuvant radiotherapy. Cancer Res Treat 48: 473-482, 2016.

15. Anscher MS, Chen L, Rabbani Z, Kang S, Larrier N, Huang H, Samulski TV, Dewhirst MW, Brizel DM, Folz RJ and Vujaskovic Z: Recent progress in defining mechanisms and potential targets for prevention of normal tissue injury after radiation therapy. Int J Radiat Oncol Biol Phys 62: 255-259, 2005.

16. Blahna MT and Hata A: Smad-mediated regulation of microRNA biosynthesis. FEBS Lett 586: 1906-1912, 2012.

17. Passaretti F, Tia M, D'Esposito V, De Pascale M, Del Corso M, Sepulveres R, Liguoro D, Valentino R, Beguinot F, Formisano P and Sammartino G: Growth-promoting action and growth factor release by different platelet derivatives. Platelets 25: 252-256, 2014.

18. Ashcroft GS: Bidirectional regulation of macrophage function by TGF-beta. Microbes Infect 1: 1275-1282, 1999. 
19. Boyd FT and Massagué J: Transforming growth factor-beta inhibition of epithelial cell proliferation linked to the expression of a 53-kDa membrane receptor. J Biol Chem 264: 2272-2278, 1989.

20. Hakenjos L, Bamberg M and Rodemann HP:TGF-beta1-mediated alterations of rat lung fibroblast differentiation resulting in the radiation-induced fibrotic phenotype. Int J Radiat Biol 76: 503-509, 2000.

21. Fajardo LF, Prionas SD, Kwan HH, Kowalski J and Allison AC: Transforming growth factor betal induces angiogenesis in vivo with a threshold pattern. Lab Invest 74: 600-608, 1996.

22. Phillips GD, Whitehead RA, Stone AM, Ruebel MW, Goodkin ML and Knighton DR: Transforming growth factor beta (TGF-B) stimulation of angiogenesis: An electron microscopic study. J Submicrosc Cytol Pathol 25: 149-155, 1993.

23. Roberts AB, McCune BK and Sporn MB: TGF-beta: Regulation of extracellular matrix. Kidney Int 41: 557-559, 1992.

24. Heldin CH and Moustakas A: Role of Smads in TGF $\beta$ signaling. Cell Tissue Res 347: 21-36, 2012.

25. Santos JI, Teixeira AL, Dias F, Gomes M, Nogueira A, Assis J and Medeiros R: Restoring TGF $\beta 1$ pathway-related microRNAs: Possible impact in metastatic prostate cancer development Tumor Biol 35: 6245-6253, 2014.

26. Bierie B and Moses HL: Transforming grow th factor beta (TGF-beta) and inflammation in cancer. Cytokine Growth Factor Rev 21: 49-59, 2010.

27. Connolly EC, Freimuth J and Akhurst RJ: Complexities of TGF- $\beta$ targeted cancer therapy. Int J Biol Sci 8: 964-978, 2012.

28. Massagué $\mathbf{J}$ and Gomis RR: The logic of TGFbeta signaling. FEBS Lett 580: 2811-2820, 2006.

29. Koh PK, Faivre-Finn C, Blackhall FH and De Ruysscher D Targeted agents in non-small cell lung cancer (NSCLC): Clinical developments and rationale for the combination with thoracic radiotherapy. Cancer Treat Rev 38: 626-640, 2012

30. Rube CE, Palm J, Erren M, Fleckenstein J, König J, Remberger K and Rübe C: Cytokine plasma levels: Reliable predictors for radiation pneumonitis? PLoS One 3: e2898, 2008.

31. Anscher MS, Crocker IR and Jirtle RL: Transforming growth factor-beta 1 expression in irradiated liver. Radiat Res 122 $77-85,1990$.

32. Zhang XJ, Sun JG, Sun J, Ming H, Wang XX, Wu L and Chen ZT: Prediction of radiation pneumonitis in lung cancer patients: A systematic review. J Cancer Res Clin Oncol 138 2103-2116, 2012

33. Anscher MS, Marks LB, Shafman TD, Clough R, Huang H, Tisch A, Munley M, Herndon JE, Garst J, Crawford J and Jirtle RL: Risk of long-term complications after TFG-beta1-guided very-high-dose thoracic radiotherapy. Int J Radiat Oncol Biol Phys 56: 988-995, 2003.

34. Novakova-Jiresova A, Van Gameren MM, Coppes RP, Kampinga $\mathrm{HH}$ and Groen $\mathrm{HJ}$ : Transforming growth factor-beta plasma dynamics and post-irradiation lung injury in lung cancer patients. Radiother Oncol 71: 183-189, 2004.

35. Chen L, Brizel DM, Rabbani ZN, Samulski TV, Farrell CL, Larrier N, Anscher MS and Vujaskovic Z: The protective effect of recombinant human keratinocyte growth factor on radiation-induced pulmonary toxicity in rats. Int $\mathrm{J}$ Radiat Oncol Biol Phys 60: 1520-1529, 2004.

36. Portess DI, Bauer G, Hill MA and O'Neill P: Low-dose irradiation of nontransformed cells stimulates the selective removal of precancerous cells via intercellular induction of apoptosis. Cancer Res 67: 1246-1253, 2007

37. De Jaeger K, Seppenwoolde Y, Kampinga HH, Boersma LJ, Belderbos JS and Lebesque JV: Significance of plasma transforming growth factor-beta levels in radiotherapy for non-small-cell lung cancer. Int J Radiat Oncol Biol Phys 58: 1378-1387, 2004

38. Anscher MS, Kong FM, Andrews K, Clough R, Marks LB, Bentel G and Jirtle RL: Plasma transforming growth factor beta1 as a predictor of radiation pneumonitis. Int J Radiat Oncol Biol Phys 41: 1029-1035, 1998

39. Anscher MS, Marks LB, Shafman TD, Clough R, Huang H, Tisch A, Munley M, Herndon JE II, Garst J, Crawford J and Jirtle RL: Using plasma transforming growth factor beta-1 during radiotherapy to select patients for dose escalation. J Clin Oncol 19: 3758-3765, 2001.

40. Wang J, Qiao XY, Lu FH, Zhou ZG, Song YZ, Huo JJ and Liu X: TGF-betal in serum and induced sputum for predicting radiation pneumonitis in patients with non-small cell lung cancer after radiotherapy. Chin J Cancer 29: 325-329, 2010
41. Lu Z, Ma Y, Zhang S, Liu F, Wan M and Luo J: Transforming growth factor- $\beta 1$ small interfering RNA inhibits growth of human embryonic lung fibroblast HFL-I cells in vitro and defends against radiation-induced lung injury in vivo. Mol Med Rep 11: 2055-2061, 2015.

42. Barthelemy-Brichant N, David JL, Bosquée L, Bury T, Seidel L, Albert A, Bartsch P, Baugnet-Mahieu L and Deneufbourg JM: Increased TGFbetal plasma level in patients with lung cancer: Potential mechanisms. Eur J Clin Invest 32: 193-198, 2002

43. Dennis PA and Rifkin DB. Cellular activation of latent transforming growth factor beta requires binding to the cation-independent mannose 6-phosphate/insulin-like growth factor type II receptor. Proc Natl Acad Sci USA 88: 580-584, 1991.

44. Yang L, Tredget EE and Ghahary A: Activation of latent transforming growth factor-betal is induced by mannose 6-phosphate/insulin-like growth factor-II receptor. Wound Repair Regen 8: 538-546, 2000.

45. Kong FM, Anscher MS, Sporn TA, Washington MK, Clough R, Barcellos-Hoff MH and Jirtle RL: Loss of heterozygosity at the mannose 6-phosphate insulin-like growth factor 2 receptor (M6P/IGF2R) locus predisposes patients to radiation-induced lung injury. Int J Radiat Oncol Biol Phys 49: 35-41, 2001.

46. Riley PA: Free radicals in biology: Oxidative stress and the effects of ionizing radiation. Int J Radiat Biol 65: 27-33, 1994

47. Barcellos-Hoff MH and Dix TA: Redox-mediated activation of latent transforming growth factor-beta 1. Mol Endocrinol 10: 1077-1083, 1996.

48. Kang SK, Rabbani ZN, Folz RJ, Golson ML, Huang H, Yu D, Samulski TS, Dewhirst MW, Anscher MS and Vujaskovic Z: Overexpression of extracellular superoxide dismutase protects mice from radiation-induced lung injury. Int J Radiat Oncol Biol Phys 57: 1056-1066, 2003.

49. Vujaskovic Z, Batinic-Haberle I, Rabbani ZN, Feng QF, Kang SK, Spasojevic I, Samulski TV, Fridovich I, Dewhirst MW and Anscher MS: A small molecular weight catalytic metalloporphyrin antioxidant with superoxide dismutase (SOD) mimetic properties protects lungs from radiation-induced injury. Free Radic Biol Med 33: 857-863, 2002.

50. Anscher MS, Kong FM, Marks LB, Bentel GC and Jirtle RL: Changes in plasma transforming growth factor beta during radiotherapy and the risk of symptomatic radiation-induced pneumonitis. Int J Radiat Oncol Biol Phys 37: 253-258, 1997.

51. Barthelemy-Brichant N, Bosquée L, Cataldo D, Corhay JL, Gustin M, Seidel L, Thiry A, Ghaye B, Nizet M, Albert A, et al: Increased IL-6 and TGF-betal concentrations in bronchoalveolar lavage fluid associated with thoracic radiotherapy. Int J Radiat Oncol Biol Phys 58: 758-767, 2004.

52. Yuan X, Liao Z, Liu Z, Wang LE, Tucker SL, Mao L, Wang XS, Martel M, Komaki R, Cox JD, et al: Single nucleotide polymorphism at rs1982073:T869C of the TGFbeta 1 gene is associated with the risk of radiation pneumonitis in patients with non-small-cell lung cancer treated with definitive radiotherapy. J Clin Oncol 27: 3370-3378, 2009.

53. Zhao L, Ji W, Zhang L, Ou G, Feng Q, Zhou Z, Lei M, Yang W and Wang L: Changes of circulating transforming growth factor-beta 1 level during radiation therapy are correlated with the prognosis of locally advanced non-small cell lung cancer. J Thorac Oncol 5: 521-525, 2010.

54. Carl C, Flindt A, Hartmann J, Dahlke M, Rades D, Dunst J, Lehnert $\mathrm{H}$, Gieseler $\mathrm{F}$ and Ungefroren $\mathrm{H}$ : Ionizing radiation induces a motile phenotype in human carcinoma cells in vitro through hyperactivation of the TGF-beta signaling pathway. Cell Mol Life Sci 73: 427-443, 2016.

55. Kelsey CR, Jackson L, Langdon S, Owzar K, Hubbs J, Vujaskovic Z, Das S and Marks LB: A polymorphism within the promoter of the TGF $\beta 1$ gene is associated with radiation sensitivity using an objective radiologic endpoint. Int J Radiat Oncol Biol Phys 82: e247-e255, 2012.

56. Bouquet F, Pal A, Pilones KA, Demaria S, Hann B, Akhurst RJ, Babb JS, Lonning SM, DeWyngaert JK, Formenti SC and Barcellos-Hoff MH: TGF $\beta 1$ inhibition increases the radiosensitivity of breast cancer cells in vitro and promotes tumor control by radiation in vivo. Clin Cancer Res 17: 6754-6765, 2011

57. Guz M, Rivero-Müller A, Okoń E, Stenzel-Bembenek A, Polberg K, Słomka M and Stepulak A: MicroRNAs-role in lung cancer. Dis Markers 2014: 218169, 2014.

58. Chan SH and Wang LH: Regulation of cancer metastasis by microRNAs. J Biomed Sci 22: 9, 2015. 
59. Muraoka-Cook RS, Kurokawa H, Koh Y, Forbes JT, Roebuck LR, Barcellos-Hoff MH, Moody SE, Chodosh LA and Arteaga CL: Conditional overexpression of active transforming growth factor beta1 in vivo accelerates metastases of transgenic mammary tumors. Cancer Res 64: 9002-9011, 2004.

60. Muraoka RS, Dumont N, Ritter CA, Dugger TC, Brantley DM, Chen J, Easterly E, Roebuck LR, Ryan S, Gotwals PJ, et al: Blockade of TGF-beta inhibits mammary tumor cell viability, migration, and metastases. J Clin Invest 109: 1551-1559, 2002.

61. Jiang Y, Chen X, Tian W, Yin X, Wang J and Yang H: The role of TGF- $\beta 1-m i R-21-R O S$ pathway in bystander responses induced by irradiated non-small-cell lung cancer cells. Br J Cancer 111: 772-780, 2014

62. Donatelli SS, Zhou JM, Gilvary DL, Eksioglu EA, Chen X, Cress WD, Haura EB, Schabath MB, Coppola D, Wei S and Djeu JY: TGF- $\beta$-inducible microRNA-183 silences tumor-associated natural killer cells. Proc Natl Acad Sci USA 111: 4203-4208, 2014.

63. Hanahan D and Weinberg RA: Hallmarks of cancer: The next generation. Cell 144: 646-674, 2011.

64. Flavell RA, Sanjabi S, Wrzesinski SH and Licona-Limón P: The polarization of immune cells in the tumor environment by TGFbeta. Nat Rev Immunol 10: 554-567, 2010.

65. Ikushima $\mathrm{H}$ and Miyazono K: TGFbeta signalling: A complex web in cancer progression. Nat Rev Cancer 10: 415-424, 2010.

66. Gal A, Sjöblom T, Fedorova L, Imreh S, Beug H and Moustakas A: Sustained TGF beta exposure suppresses Smad and non-Smad signalling in mammary epithelial cells, leading to EMT and inhibition of growth arrest and apoptosis. Oncogene 27: 1218-1230, 2008.

67. Shintani Y, Okimura A, Sato K, Nakagiri T, Kadota Y, Inoue M Sawabata N, Minami M, Ikeda N, Kawahara K, et al: Epithelial to mesenchymal transition is a determinant of sensitivity to chemoradiotherapy in non-small cell lung cancer. Ann Thorac Surg 92: 1794-1804, 2011.
68. Mehta V: Radiation pneumonitis and pulmonary fibrosis in non-small-cell lung cancer: Pulmonary function, prediction, and prevention. Int J Radiat Oncol Biol Phys 63: 5-24, 2005

69. Kong FM, Pan C, Eisbruch A and Ten Haken RK: Physical models and simpler dosimetric descriptors of radiation late toxicity. Semin Radiat Oncol 17: 108-120, 2007.

70. Milano MT, Constine LS and Okunieff P: Normal tissue tolerance dose metrics for radiation therapy of major organs. Semin Radiat Oncol 17: 131-140, 2007.

71. Anscher MS: Targeting the TGF-beta1 pathway to prevent normal tissue injury after cancer therapy. Oncologist 15: 350-359, 2010.

72. Anscher MS, Thrasher B, Rabbani Z, Teicher B and Vujaskovic Z: Antitransforming growth factor-beta antibody 1D11 ameliorates normal tissue damage caused by high-dose radiation. Int J Radiat Oncol Biol Phys 65: 876-881, 2006.

73. Daniels CE, Wilkes MC, Edens M, Kottom TJ, Murphy SJ, Limper $\mathrm{AH}$ and Leof EB: Imatinib mesylate inhibits the profibrogenic activity of TGF-beta and prevents bleomycin-mediated lung fibrosis. J Clin Invest 114: 1308-1316, 2004.

74. Haydont V, Mathé D, Bourgier C, Abdelali J, Aigueperse J, Bourhis $\mathrm{J}$ and Vozenin-Brotons MC: Induction of CTGF by TGF-betal in normal and radiation enteritis human smooth muscle cells: Smad/Rho balance and therapeutic perspectives. Radiother Oncol 76: 219-225, 2005.

75. Haydont V, Riser BL, Aigueperse J and Vozenin-Brotons MC: Specific signals involved in the long-term maintenance of radiation-induced fibrogenic differentiation: A role for $\mathrm{CCN} 2$ and low concentration of TGF-beta1. Am J Physiol Cell Physiol 294: C1332-C1341, 2008

76. Rabbani ZN, Anscher MS, Zhang X, Chen L, Samulski TV, Li CY and Vujaskovic Z: Soluble TGFbeta type II receptor gene therapy ameliorates acute radiation-induced pulmonary injury in rats. Int J Radiat Oncol Biol Phys 57: 563-572, 2003. 